\title{
HYBRID-TYPE OF FIXED-SET RESULTS IN BANACH ALGEBRAS INVOLVING THE SUM AND THE PRODUCT OF MULTI-VALUED MAPPINGS UNDER WEAK TOPOLOGY
}

\author{
KHaled Ben Amara ${ }^{1}$, Aref JERIBI ${ }^{1}$, and najib Kaddachi ${ }^{1}$ \\ ${ }^{1}$ University of Sfax Faculty of Sciences of Sfax
}

May 6, 2020

\begin{abstract}
In this manuscript, by means of the technique of measures of weak noncompactness, we prove some fixed set results for the sum and the product of $(\mathrm{p}+1)$ multi-valued mappings $\mathrm{Pp} i=1 \mathrm{~A} \mathrm{Bi}$; acting on Banach algebras satisfying a certain sequential condition $(\mathrm{P})$ under weak topology. In addition, by using a new definition of the multi-valued mapping I A ; we get new fixed set theorems for the mappings of the form I A 1 Pni $=1$ Bi under some suitable conditions on the operators A; B1; : : : ; Bp in Banach algebras. Applications to the theory of self-similarity are also given.
\end{abstract}

\section{Hosted file}

Somme A Bi (1) (1).pdf available at https://authorea.com/users/317330/articles/447435hybrid-type-of-fixed-set-results-in-banach-algebras-involving-the-sum-and-the-productof-multi-valued-mappings-under-weak-topology 